ORIGINAL ARTICLE

\title{
A COMPARATIVE STUDY BETWEEN TRANSMUSCULAR QUADRATUS LUMBORUM BLOCK AND OBLIQUE SUBCOSTAL TRANSVERSUS ABDOMINIS PLANE BLOCK FOR ANALGESIA FOLLOWING UPPER ABDOMINAL SURGERIES
}

\author{
Ashraf Abd-Allah Turki *, Lobna Taha El-Dorgham, Dalal El-Sayed Soud, Nahla Mohammed \\ Amin \\ Anesthesia and surgical intensive care Department, Faculty of Medicine, Zagazig University. \\ Zagazig, Egypt
}

\begin{abstract}
*Corresponding author:
Ashraf Abd-Allah Turki

Anesthesia and surgical intensive care Department, Faculty of Medicine,

Zagazig University.

Zagazig, Egypt

email:

dr.ashraf.anesthesia@gmail.co

m, mobile; 01009812398
\end{abstract}

$\begin{array}{ll}\text { Submit Date } & 2019-03-19 \\ \text { Revise Date } & 2019-03-31 \\ \text { Accept Date } & 2019-04-02\end{array}$

\begin{abstract}
Background: Ultrasound (US)-guided transmuscular quadratus lumborum (TQL) block and oblique subcostal transversus abdominis plane (OSTAP) block are components of multimodal analgesia for abdominal surgeries. The aim of the study is to compare the analgesic efficacy of US-guided TQL block versus US-guided OSTAP block after upper abdominal surgeries. Methods: This prospective randomized study was conducted on 40 patients scheduled for elective open upper abdominal surgery under general anesthesia. Patients were randomly allocated into 2 groups; OSTAP Group (20 patients) received US-guided OSTAP block, and TQL Group (20 patients) received USguided TQL block. At the end of surgical procedure, while patients were still under general anesthesia, each group received $30 \mathrm{~mL}$ bupivacaine $0.25 \%$. Postoperative measurements included pain scores, time to first opioid analgesic request, postoperative total opioid consumption, patient satisfaction, and complications.

Results: Patients of TQL group had statistically significant lower $24 \mathrm{~h}$ postoperative total morphine consumption than patients of OSTAP group $(13.25 \pm 2.88 \mathrm{mg}$ and $20.10 \pm 3.21 \mathrm{mg}$, respectively, $P<0.001)$, and longer time to first opioid analgesic request $(373.25 \pm 18.76 \mathrm{~min}$. and $245.75 \pm 11.50 \mathrm{~min}$., respectively, $P<0.001$ ). Patients received TQL block had also statistically significant lower postoperative pain scores, less frequent morphine doses, and more patient satisfaction.

Conclusion: US-guided TQL block is more effective postoperative analgesic modality than US-guided OSTAP block in patients undergoing elective open upper abdominal surgery under general anesthesia.

Keywords: Transmuscular quadratus lumborum block, Oblique subcostal TAP block, Postoperative pain relief, Abdominal surgeries.
\end{abstract}

\section{INTRODUCTION}

$\mathrm{O}$ ptimal analgesia is valuable for adequate recovery after major abdominal surgery. US-guided OSTAP block, described by Hebbard et al., allows efficient analgesia for both upper and lower abdominal surgeries[1]. OSTAP catheters had been used as an alternative to epidural analgesia after upper abdominal surgery[2].

Because TAP blockade provides only somatic anesthesia of the abdominal wall, quadratus lumborum blocks (QLBs) have been adopted to accomplish somatic and visceral analgesia of the abdominal wall. Blanco described QLB1 and QLB2 with local 
anesthetic (LA) injection in the antero-lateral aspect and in the posterior aspect of QL muscle, respectively[3]. TQL block was described by Borglum et al., with LA injection between QL and psoas major muscles[4]. Comparative studies have shown that QLB covered a topographically wider field (T7-T12 for QLB versus T10-T12 for TAP), and yielded longer analgesia compared to TAP block (24-48 h for QLB versus 8-12 h for TAP block) $[5,6]$.

The aim of this study was to compare between US-guided TQL block and US-guided OSTAP block for postoperative analgesia after upper abdominal surgeries, regarding pain scores during rest and movement, time to first opioid analgesic request postoperative, frequency of opioid administration in the first $24 \mathrm{~h}$ postoperative, $24 \mathrm{~h}$ postoperative total opioid consumption, patient satisfaction, and complications.

\section{METHODS}

After obtaining approval from institutional review board (IRB), this prospective randomized study was carried out at Zagazig university hospitals on 40 patients aged from 18-60 years old, of both sexes, with body mass index (BMI) $<30 \mathrm{~kg} / \mathrm{m}^{2}$ and ASA physical status I, II, or III, scheduled for elective open upper abdominal surgery under general anesthesia.

Exclusion criteria included; bilateral abdominal surgeries or midline surgical incision, allergy to any of the drugs used in the study, contraindications of regional anesthesia, e.g., coagulopathy or infection at site of injection, drug dependence or chronic analgesic use, and psychiatric disorders.

Randomization was done using computer generated number tables and concealed using sealed opaque envelope. Patients and data collector were blind to group assignment. Once enrolled in the study, patients were randomly assigned into 2 groups; OSTAP Group (20 patients) received US-guided OSTAP block and TQL Group (20 patients) received US-guided TQL block (Fig. 1).

Routine preoperative assessment was done to all patients by careful history taking, clinical examination and laboratory investigations. Procedure explanation to the patient was done the day before surgery.

Written informed consent was obtained from all participants. The work has been carried out in accordance with The Code of Ethics of the World Medical Association (Declaration of Helsinki) for studies involving humans.

Patients were instructed how to represent their level of pain using the visual analogue scale $(V A S)$, in which $\mathbf{0}=$ no pain and $\mathbf{1 0}=$ worst pain imaginable.

Hemodynamic parameters including heart rate $(H R)$ and mean arterial blood pressure $(M A P)$, were recorded after receiving intravenous (IV) $2 \mathrm{mg}$ midazolam (baseline data) and intraoperative every $5 \mathrm{~min}$. for 15 min., then every $15 \mathrm{~min}$. afterwards till the end of surgery.

General anesthesia was induced to all patients using IV fentanyl $(1 \mu \mathrm{g} / \mathrm{kg})$, propofol $(2 \mathrm{mg} / \mathrm{kg})$ and cis-atracurium $(0.15 \mathrm{mg} / \mathrm{kg})$. Following endotracheal intubation, volumecontrolled mechanical ventilation was used to maintain end-tidal carbon dioxide of $35-40$ $\mathrm{mmHg}$.

Anesthesia was maintained with oxygen and $1.5 \%$ isoflurane. Additional doses of cisatracurium $(0.04 \mathrm{mg} / \mathrm{kg})$ were given when needed, guided by nerve stimulator. Fentanyl $(0.5-1 \mu \mathrm{g} / \mathrm{kg}$ ) was administered IV for any intraoperative increase in HR or MAP above $20 \%$ of baseline.

At the end of surgical procedure and after wound closure, while patients were still under general anesthesia, patients allocated to OSTAP group received US-guided OSTAP block, and patients allocated to TQL group received USguided TQL block.

\section{Technique of US-guided OSTAP Block:}

While the patient was supine, the abdomen was exposed between the costal margin and iliac crest. Under complete aseptic precautions, the linear US probe $(6-13 \mathrm{MHz})$ of SonoSite MTurbo US machine (M-Turbo; SonoSite, Inc., Bothell, WA, USA) was placed obliquely along the subcostal margin near the midline. Rectus abdominis and the underlying transversus 
abdominis muscles were identified. 20 gauge spinal needle was inserted in-plane through rectus muscle, and advanced until its tip was in the fascial plane between rectus abdominis and transversus abdominis muscles. $30 \mathrm{~mL}$ of $0.25 \%$ bupivacaine were administered in the TAP with hydrodissection by the needle passing along the oblique subcostal line extending infero-laterally from xyphoid process toward the anterior part of iliac crest.

\section{Technique of US-Guided Transmuscular QL (TQL) Block:}

Patient was placed in the lateral position with the side to be anesthetized turned upwards. Under complete aseptic precautions, curved US probe $(2-5 \mathrm{MHz})$ of SonoSite M-Turbo US machine was placed in the midaxillary line immediately above the iliac crest to identify the three muscles of the anterior abdominal wall (external oblique, internal oblique and transversus abdominis). US probe was then moved dorsally until visualization of the shamrock sign; with psoas major muscle anteriorly, erector spinae muscle posteriorly, and $Q L$ muscle adherent to the apex of the transverse process of LA vertebral body being the three leaves, and the transverse process of L4 being the stem. 20 gauge spinal needle was inserted in-plane from anterior to posterior, and advanced through the QL muscle. $30 \mathrm{~mL}$ of $0.25 \%$ bupivacaine were injected in the fascial plane between the $Q L$ and psoas major muscles.

After completion of blockade, isoflurane was discontinued, residual neuromuscular blockade was antagonized using neostigmine (0.05 $\mathrm{mg} / \mathrm{kg})$ and atropine $(0.02 \mathrm{mg} / \mathrm{kg})$ administered IV, at $50 \%$ responsiveness to train of four (TOF) stimulus. Awake extubation was done when the patient could follow verbal commands with TOF response at $90 \%$ of control. Surgical time (defined as the time between incision and completion of dressing) was recorded.

After recovery from general anesthesia, sensory blockade was confirmed using pin prick on the block side using Hollmen scale for sensory block as follows[7]. $\mathbf{1}=$ Normal sensation of pinprick, $\mathbf{2}=$ Pin prick felt as sharp pointed but weaker when compared with same area in the other side, $\mathbf{3}=$ Pin prick felt as touch with blunt object, and $\mathbf{4}=$ No perception of pin prick. Hollmen scores were recorded at an interval of $5 \mathrm{~min}$. till a complete sensory block was achieved, i.e., Hollmen score $=4$ (successful block).

After patient discharge to the ward, all patients received IV multimodal analgesia in the form of; paracetamol ( $1 \mathrm{~g}$ every $8 \mathrm{~h}$ ), ketorolac (15 $\mathrm{mg}$ every $6 \mathrm{~h})$, and also morphine, as 1-2 $\mathrm{mg}$ IV bolus at each dose, was given when VAS equal or above 3 .

\section{Points of Comparison:}

Patients' Characteristics (including age, sex, BMI, and ASA physical status), Surgery Type, and Surgical Time.

Postoperative Hemodynamic Measurements; $H R, M A P$, respiratory rate $(R R)$, and oxygen saturation ( $\mathrm{SpO} 2$ ) were recorded immediately postoperative, then every hour for the first $4 \mathrm{~h}$, and then every $4 \mathrm{~h}$ till the end of the first $24 \mathrm{~h}$ postoperative.

Postoperative Pain; was assessed during rest and movement (sitting from lying down position) using $V A S$ which was recorded by the data collector who was blind to the intervention done to the patient. Pain assessment was done at $1,2,4,6,8,12,18$ and $24 \mathrm{~h}$ postoperative.

Postoperative Opioid Consumption; it includes:Time to first opioid analgesic request postoperative, frequency of opioid administration in the first $24 \mathrm{~h}$ postoperative, and twenty four hours postoperative total opioid consumption.

Postoperative Complications;

Opioid side effects;

A. Sedation: was measured using Pasero opioidinduced sedation scale (POSS); $\mathbf{S}=$ Sleep, easy to arouse, $\mathbf{1}=$ Awake and alert, $\mathbf{2}=$ Slightly drowsy, easily aroused, $\mathbf{3}=$ Frequently drowsy, arousable, drifts off to sleep during conversation, $\mathbf{4}=$ Somnolent, minimal or no response to verbal and physical stimulation[8].

B. Respiratory depression: defined as decreased respiratory rate $(R R)<8-10$ breaths/minute or decreased $\mathrm{SpO} 2<90 \%[9]$. 
C. Postoperative nausea and vomiting (PONV): Ondansetron (4 mg) was administered IV in case of reported nausea and/or vomiting. Frequency of PONV and total requirements of ondansetron in the first $24 \mathrm{~h}$ postoperative were recorded.

Technical complications; visceral injury, hematoma formation, lower extremity weakness, and local anesthetic systemic toxicity (LAST).

Patient Satisfaction; was also considered and recorded at the end of the first $24 \mathrm{~h}$ postoperative using a 5-point scale as follows[10]. 1 = Completely dissatisfied, 2 = Dissatisfied, $\mathbf{3}=$ Neither satisfied nor dissatisfied, 4 = Satisfied, and 5 = Completely satisfied.

\section{Study Outcome Measures:}

Primary Outcome Measure: Twenty four hours postoperative total opioid consumption.

Secondary Outcome Measures: Time to first opioid analgesic request postoperative, postoperative VAS scores during rest and movement, and postoperative complications.

\section{Sample Size:}

Sample size was calculated to be $\mathbf{4 0}$ (20 for each group), using open epi at confidence level $95 \%$ and $80 \%$ power of test, assuming that the mean and standard deviation difference of $24 \mathrm{~h}$ IV morphine consumption between the OSTAP and TQL groups were $16.76 \pm 2.7$ and $14.8 \pm$ 1.5 , respectively[11].

\section{Statistical Analysis:}

Data were analyzed using IBM SPSS advanced statistics (Statistical Package for Social Sciences), version 22 (SPSS Inc., Chicago, IL). Numerical data was described as mean and standard deviation or median and range as appropriate. Comparisons between categorical variable were performed using chi square test or fissure exact test when assumption of chi square was not fulfilled. Mann Whitney test was used to compare nonnormally distributed numerical variable between the two groups. The probability value $(\mathrm{p}$-value $) \leq \mathbf{0 . 0 5}$ was considered statistically significant.

\section{RESULTS}

There were no statistically significant differences between the two groups regarding patients' characteristics, surgery type, or surgical time, $\boldsymbol{P}>\mathbf{0 . 0 5}$ (Table 1).

Patients of the OSTAP group had statistically significant higher postoperative $H R$ and MAP than patients of the TQL group in the first $8 \mathrm{~h}$ postoperative, $\boldsymbol{P}<\mathbf{0 . 0 5}$. In the later $16 \mathrm{~h}$, although HR and MAP were still higher in patients of the OSTAP group, but were not statistically significant from that of patients of the TQL group, $\boldsymbol{P}>\mathbf{0 . 0 5}$

There were no statistically significant differences between the two groups regarding postoperative $\mathrm{SpO} 2$ or $\mathrm{RR}, \boldsymbol{P}>\mathbf{0 . 0 5}$

Patients of the OSTAP group had statistically significant higher VAS scores during rest and movement than patients of the TQL group in the first $8 \mathrm{~h}$ postoperative, $\boldsymbol{P}<\mathbf{0 . 0 5}$. In the later $16 \mathrm{~h}$, although VAS scores during rest and movement were still higher in patients of the OSTAP group, but were not statistically significant from that of patients of the TQL group, $P>0.05$ (Fig. $2 \& 3$ ).

Patients of the OSTAP group had high statistically significant shorter time to first opioid analgesic request postoperative $(245.75 \pm 11.50 \mathrm{~min}$.$) than patients of the TQL$ group (373.25 $\pm 18.76 \mathrm{~min}$.), $\boldsymbol{P}<\mathbf{0 . 0 0 1}$ (Fig. 4).

Patients of the OSTAP group required high statistically significant more frequent morphine doses than patients of the TQL group, $\boldsymbol{P}<$ 0.001

Patients of the OSTAP group required high statistically significant more 24 h postoperative total morphine consumption $(20.10 \pm 3.21 \mathrm{mg})$ than patients of the TQL group (13.25 \pm 2.88 mg), $\quad \boldsymbol{P}<0.001$ (Fig. 5).

None of the patients in the two groups suffered from either sedation or respiratory depression. 3 patients $(15 \%)$ in the OSTAP group, and $1(5 \%)$ patient in the TQL group suffered from one attack of PONV that was treated by IV ondansetron $4 \mathrm{mg}$ administered once. There was no statistically significant difference between the two groups regarding 
the incidence of opioid side effects, However, PONV was higher in OSTAP group, $\boldsymbol{P}>\mathbf{0 . 0 5}$

None of the patients in the two groups developed either visceral injury, hematoma at site of injection, lower extremity weakness, or LAST.
At the end of the first $24 \mathrm{~h}$ postoperative, patients of the TQL group had statistically significant higher satisfaction regarding postoperative analgesia than patients of the OSTAP group, $\boldsymbol{P}<\mathbf{0 . 0 5}$ (Table 2).

Table (1): Patients' characteristics, Surgery Type \& Surgical Time

Data were represented as mean \pm standard deviation or as a number (\%)

\begin{tabular}{|c|c|c|c|c|}
\hline Groups & $\begin{array}{c}\text { OSTAP } \\
\text { Group } \\
(\mathbf{n = 2 0})\end{array}$ & $\begin{array}{c}\text { TQL Group } \\
(\mathbf{n = 2 0})\end{array}$ & $\begin{array}{c}\text { T test }^{\#} \\
\text { Chi-square test }\end{array}$
\end{tabular} \mid \begin{tabular}{c} 
P-value \\
\hline Patients' characteristics
\end{tabular}

OSTAP; oblique subcostal transversus abdominis plane, TQL; transmuscular quadratus lumborum,

BMI; body mass index, ASA; American society of anesthesiologists.

Statistical analysis was done by using $\mathbf{t}$ test ${ }^{\#}$ and chi-square test ${ }^{\# \#}$.

No statistically significant differences between the two groups, $\boldsymbol{P}>0.05$

Table (2): Comparison between the Two Groups Regarding the Patient Satisfaction

Data were represented as a number $(\%)$

\begin{tabular}{|c|c|c|c|c|}
\hline $\begin{array}{c}\text { Groups } \\
\text { Satisfaction Score }\end{array}$ & $\begin{array}{c}\text { OSTAP } \\
(\mathbf{n = 2 0})\end{array}$ & $\begin{array}{c}\text { TQL } \\
(\mathbf{n = 2 0})\end{array}$ & $\begin{array}{c}\text { Chi-square } \\
\text { test }\end{array}$ & P-value \\
\hline $\mathbf{3}$ & $8.0(40.0 \%)$ & $3.0(15.0 \%)$ & 23.03 & \multirow{2}{*}{$0.006^{*}$} \\
\hline $\mathbf{4}$ & $11.0(55.0 \%)$ & $7.0(35.0 \%)$ & & \\
\hline $\mathbf{5}$ & $1.0(5.0 \%)$ & $10.0(50.0 \%)$ & & \\
\hline
\end{tabular}

OSTAP; oblique subcostal transversus abdominis plane, TQL; transmuscular quadratus lumborum.

Satisfaction Score; 3 = Neither satisfied nor dissatisfied, 4 = Satisfied, and $\mathbf{5}=$ Completely satisfied.

Statistical analysis was done by using chi-square test.

(*) Statistically significant difference between the two groups, $\boldsymbol{P}<\mathbf{0 . 0 5}$ 


\section{Enrolment}
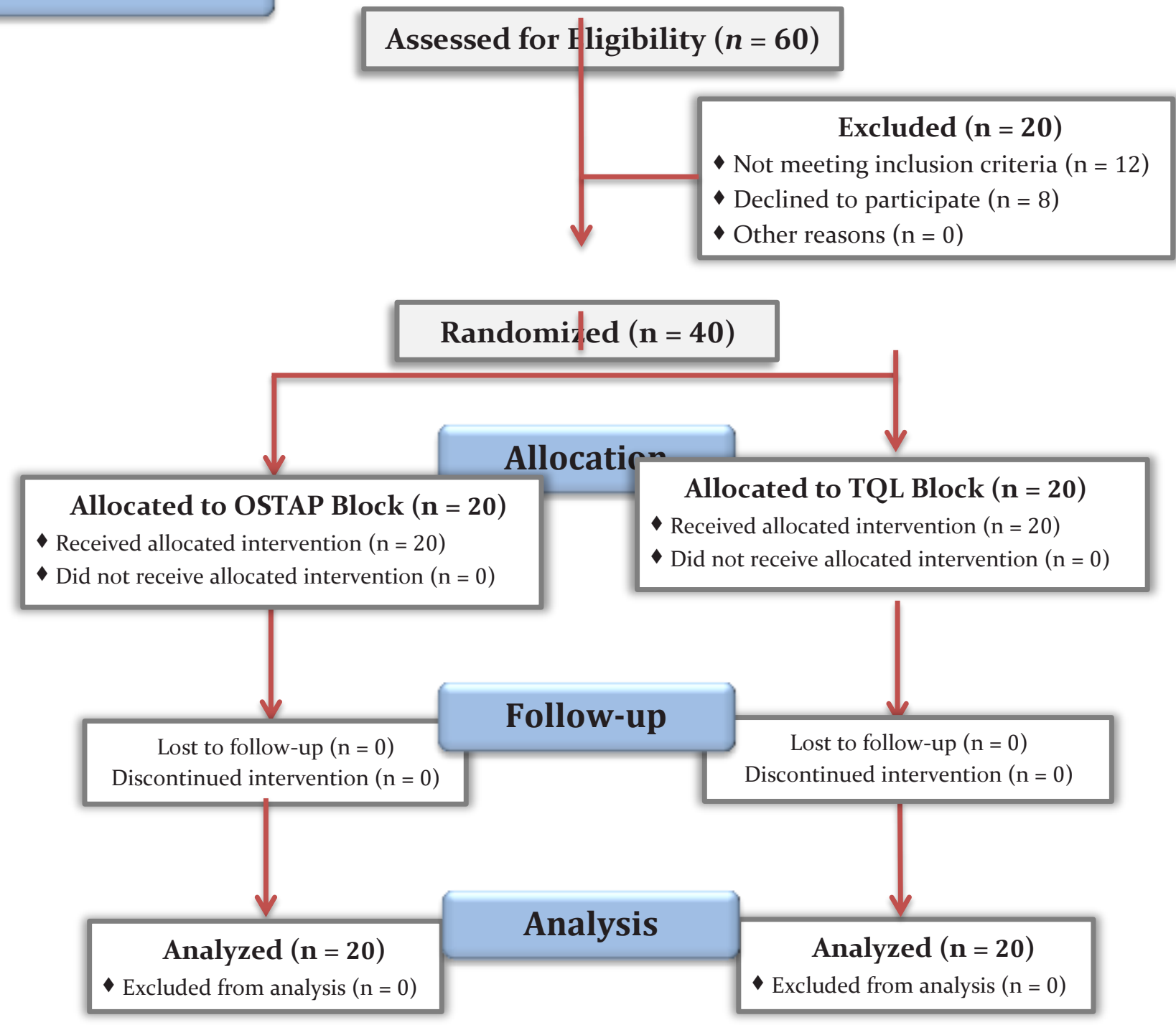

Fig. 1: CONSORT flow diagram.

OSTAP; oblique subcostal transversus abdominis plane, TQL; transmuscular quadratus lumborum. 


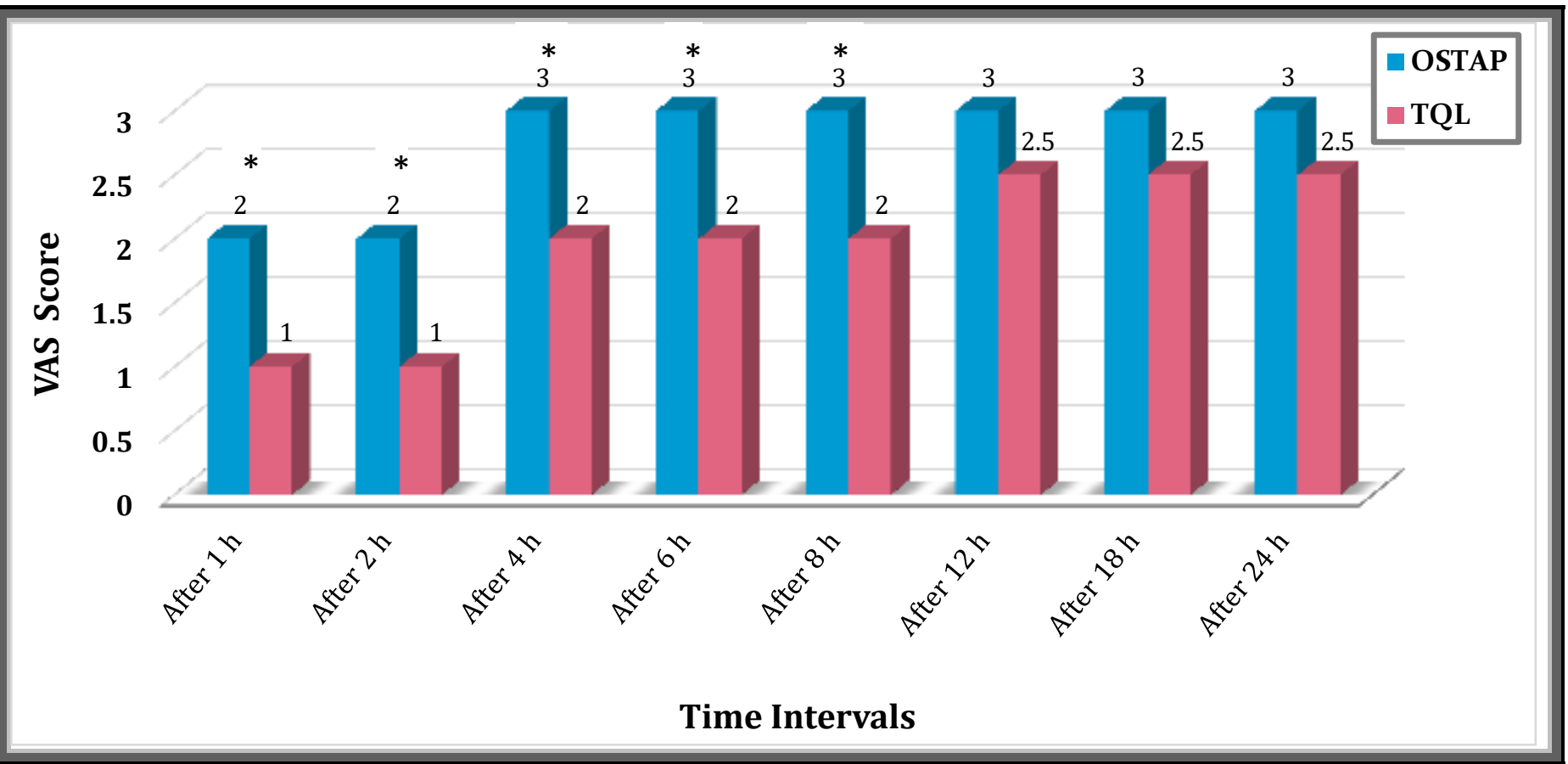

Fig. 2: Comparison between the two groups regarding postoperative VAS scores during rest.

were represented as a number (score). OSTAP; oblique subcostal transversus abdominis plane, TQL; transmuscular quadratus lumborum, VAS; visual analogue scale. (*) Statistically significant difference between the two groups, $\boldsymbol{P}<\boldsymbol{0 . 0 5}$. Statistical analysis was done by using Mann Whitney test.

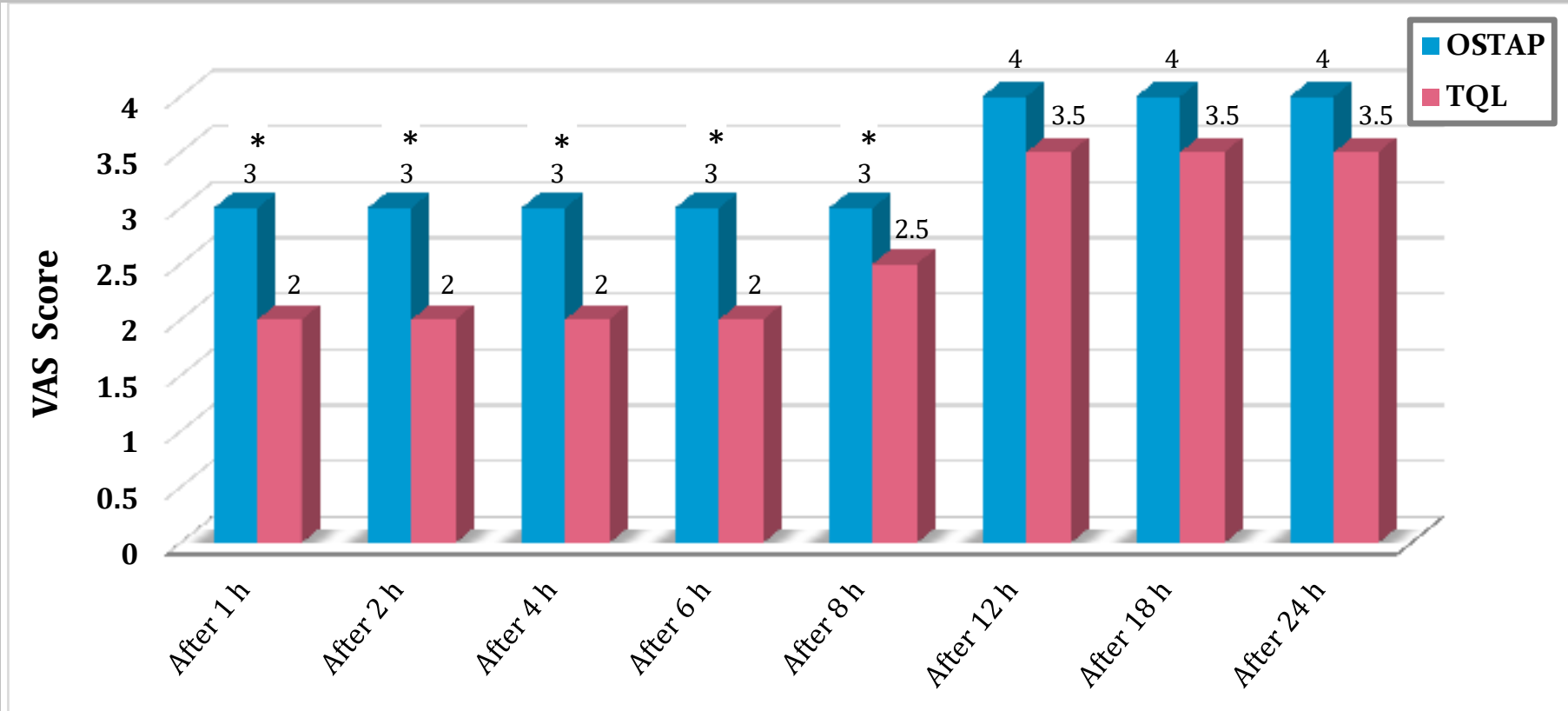

Time Intervals

Fig. 3: Comparison between the two groups regarding postoperative VAS scores during movement. Data were represented as a number (score). OSTAP; oblique subcostal transversus abdominis plane, TQL; transmuscular quadratus lumborum, VAS; visual analogue scale. (*) Statistically significant difference between the two groups, $\boldsymbol{P}<\boldsymbol{0 . 0 5}$. Statistical analysis was done by using Mann Whitney test. 


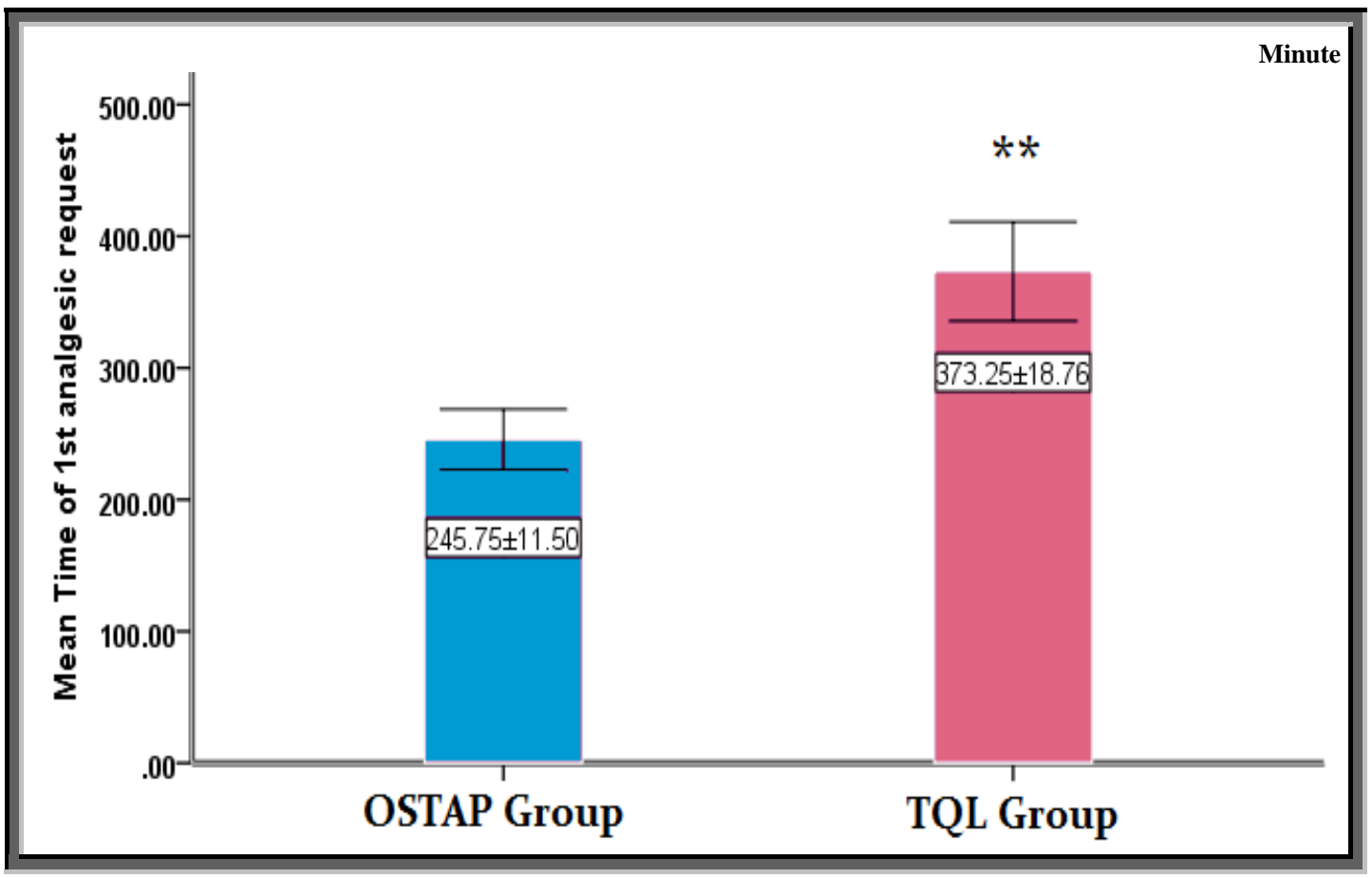

Fig. 4: Comparison between the two groups regarding the time to first opioid analgesic request postoperative.

Data were represented as mean \pm standard deviation. transversus abdominis plane, TQL; Transmuscular quadratus lumborum.

(**) High statistically significant difference between the two groups, $\boldsymbol{P}<\mathbf{0 . 0 0 1}$.

Statistical analysis was done by using Mann Whitney test.

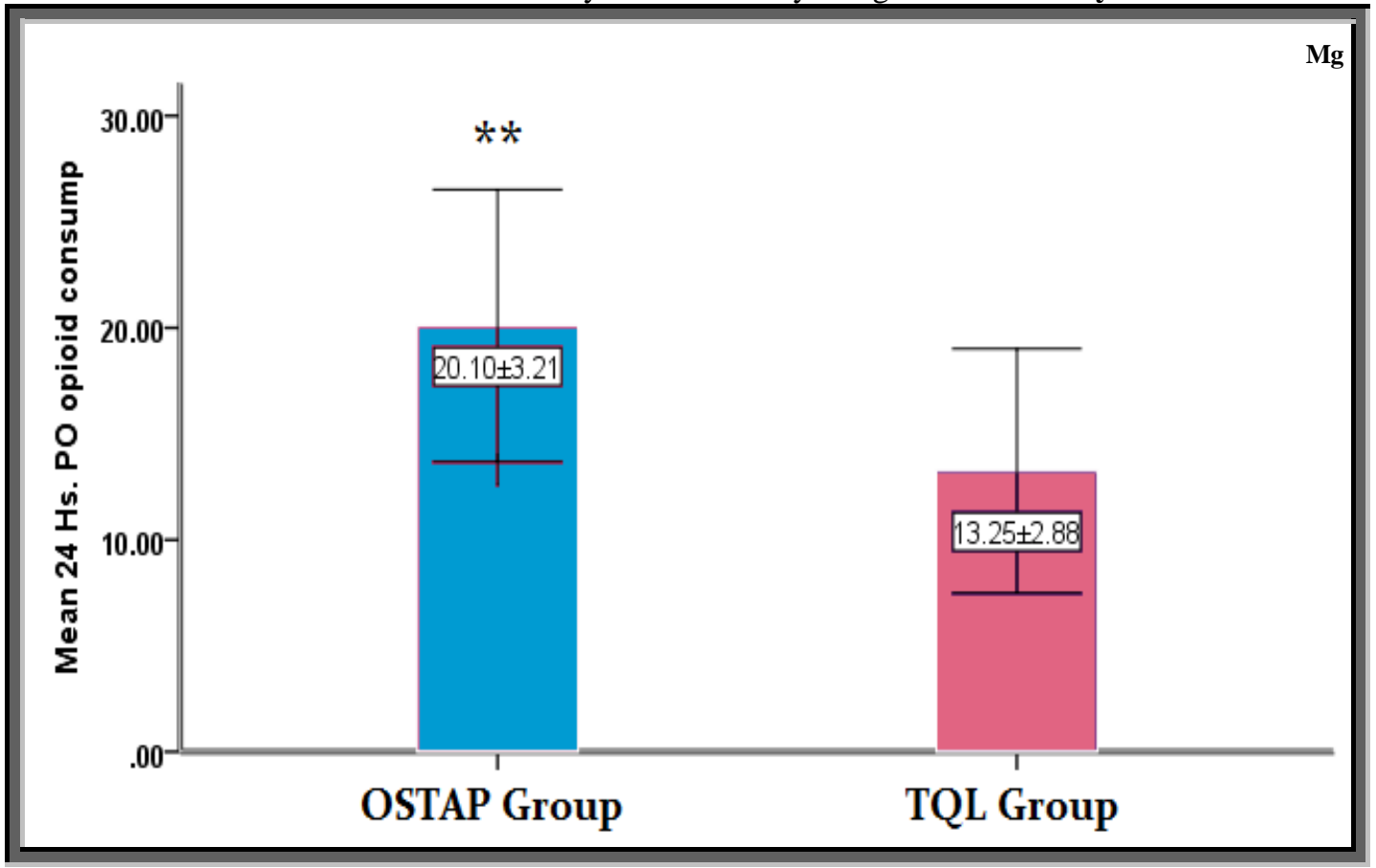

Fig. 5: Comparison between the two groups regarding $24 \mathrm{~h}$ postoperative total morphine consumption. Data were represented as mean \pm standard deviation. OSTAP; Oblique subcostal transversus abdominis plane, TQL; Transmuscular quadratus lumborum. (**) High statistically significant difference between the two groups, $\boldsymbol{P}<\mathbf{0 . 0 0 1}$. Statistical analysis was done by using $\mathbf{t}$ test. 


\section{DISCUSSION}

The main findings of the current study were that patients underwent elective open upper abdominal surgery under general anesthesia and received US-guided TQL block had less postoperative pain scores during rest and movement, longer time to first opioid analgesic request postoperative, less frequent morphine doses in the first $24 \mathrm{~h}$ postoperative, lower $24 \mathrm{~h}$ postoperative total morphine consumption, and more patient satisfaction when compared to patients received US-guided OSTAP block.

The current study, according to our knowledge, was the first study that compared between US-guided TQL block and US-guided OSTAP block for postoperative analgesia after open upper abdominal surgeries.

Kim et al. had published a review on the role of TAP block as a part of enhanced recovery after surgery (ERAS) protocol, and found that TAP block resulted in significantly less opioid use and less postoperative pain. Also, noninferiority was shown in comparison to thoracic epidural[12].

Results of the current study agreed with findings of Shin et al., who compared OSTAP block versus TAP block and versus conventional care in laparoscopic cholecystectomy, and reported that OSTAP block group had lower pain scores and lower postoperative $24 \mathrm{~h}$ opioid consumption than the other two groups[13].

Results of the current study also agreed with findings of Breazu et al., who conducted a prospective placebo controlled study of the efficacy of OSTAP block in laparoscopic cholecystectomy, and found that patients received OSTAP block with bupivacaine $0.25 \%$ had lower pain scores and lower postoperative $24 \mathrm{~h}$ opioid consumption than the placebo group[14].

A review by Akerman et al., discussing the role of QLB in ERAS protocols, reported that QLB had the potential to significantly facilitate and improve postoperative pain therapy. Improved early oral intake and early mobilization could be more easily achieved with good pain control, and QLB had a great potential in this area of ERAS[15].

Baidya et al. demonstrated in their case series of 5 children aged 3-5 years, that TQL block with $0.5 \mathrm{~mL} / \mathrm{kg}$ of $0.2 \%$ ropivacaine provided excellent postoperative analgesia following lumbotomy and pyeloplasty surgery, which agreed with results of the current study [16].

Results of the current study also agreed with results of Blanco et al. who studied the effects of QLB versus placebo on patient controlled analgesia morphine doses and demands after cesarean section. They found that patients received QLB had significantly less morphine consumption than the control group at 6 and 12 $\mathrm{h}$ postoperative, and also had significantly fewer morphine demands postoperative. Pain scores were also significantly better in the QLB group than in the control patients[17].

Results of the current study were also in accordance with results of Blanco and his coworkers, who compared the efficacy of TAP versus QLB2 blocks for postoperative analgesia in cesarean delivery. They reported that QLB2 block was superior to TAP block with respect to the duration of effect, pain relief, and opioid consumption. QLB2 produced wider and longer sensory blockade compared to the TAP block (T7-T12 for QLB2 versus T10-T12 for TAP, and $24-48 \mathrm{~h}$ for QLB2 versus $8-12 \mathrm{~h}$ for TAP block) [5].

Consistent with the current study results also, Murouchi et al. showed that, following laparoscopic ovarian surgery, QLB, could spread to T7- T12 and could last for almost 24 $\mathrm{h}$, while lateral TAP block could spread to only T10 - T12 and could last for only $7 \mathrm{~h}[6]$.

Results of the current study also agreed with findings of Elsharkawy et al., who compared left TQL block versus right TAP block using liposomal bupivacaine in a patient undergoing subtotal colectomy through a midline incision extending from above the umbilicus to pubic symphysis. This patient experienced consistent sensory blockade in the corresponding 
dermatomal distribution for about $48 \mathrm{~h}$ on TQL block side; however, TAP block on the contralateral side did not cover the whole length of the incision. They reported that TQL block could create more effective sensory blockade and analgesia along mid and lower thoracic dermatomes[18].

Results of the current study were also in accordance with findings of Jadon et al., who provided postoperative analgesia using bilateral TQL blocks and LA infusion through inserting catheters in a patient with cardiac disease and underwent hysterectomy operation. They observed that TQL block was an effective technique for postoperative pain relief after hysterectomy surgery in a high risk patient[19].

The current study results also agreed with the findings of $\ddot{O} k s \ddot{i z}$ et al., who compared QLB2 versus TAP blocks for postoperative pain relief in children undergoing lower abdominal surgery. Results of their study showed that the QLB2 provided longer and more effective postoperative analgesia, lower pain scores, and more parent satisfaction compared with TAP block [20].

Two theories could explain the superior analgesic effect of QLBs when compared with TAP blocks. First, QLBs might facilitate $L A$ spread into the thoracic paravertebral space, theoretically prolonging the block and achieving visceral pain relief. Second, $L A$ spread during $Q L B s$ to a network of sympathetic nerves in the thoracolumbar fascia could explain the long-lasting analgesic effect [5].

Limitations of the current study were that we did not assess dermatomal levels of the two blocks, as we focused on morphine consumption. However, the exact analgesic effectiveness of the OSTAP and TQL blocks under study was more reliably reflected by VAS pain score and opioid consumption rather than the sensory level.

\section{CONCLUSION}

US-guided TQL block is more effective postoperative analgesic modality than USguided OSTAP block in patients undergoing elective open upper abdominal surgery under general anesthesia. TQL block is associated with less postoperative pain scores, less postoperative opioid consumption, and more patient satisfaction compared to OSTAP block.

\section{Declaration of interest}

The authors report no conflicts of interest. The authors alone are responsible for the content and writing of the paper.

\section{Funding information}

None declared

\section{REFERENCES}

1. Hebbard PD, Barrington MJ, and Vasey C. Ultrasound-guided continuous oblique subcostal transversus abdominis plane blockade: description of anatomy and clinical technique. Regional anesthesia and pain medicine. 2010;35(5):436-41.

2. Niraj G, Kelkar A, and Fox AJA. Oblique sub-costal transversus abdominis plane (TAP) catheters: an alternative to epidural analgesia after upper abdominal surgery. Anaesthesia. 2009;64(10):1137-40.

3. Blanco R and McDonnell J. Optimal point of injection: the quadratus lumborum type I and II blocks. Anaesthesia. 2014;1550.

4. Børglum J, Moriggl B, Jensen K, Lønnqvist P-A, Christensen AF, Sauter A, et al. Ultrasoundguided transmuscular quadratus lumborum blockade. BJA: British Journal of Anaesthesia. 2013;111(eLetters Supplement).

5. Blanco R, Ansari T, Riad W, and Shetty N. Quadratus lumborum block versus transversus abdominis plane block for postoperative pain after cesarean delivery: a randomized controlled trial. Regional anesthesia and pain medicine. 2016;41(6):757-62.

6. Murouchi T, Iwasaki S, and Yamakage M. Quadratus lumborum block: analgesic effects and chronological ropivacaine concentrations after laparoscopic surgery. Regional anesthesia and pain medicine. 2016;41(2):146-50.

7. Capogna G, Celleno D, Laudano D, and Giunta F. Alkalinization of local anesthetics. Which block, which local anesthetic? Regional anesthesia. 1995;20(5):369-77.

8. Pasero C. Assessment of sedation during opioid administration for pain management. Journal of PeriAnesthesia Nursing. 2009;24(3):186-90.

9. Fitzgibbon DR and McQuay H. Respiratory Depression: Incidence, Diagnosis, and Treatment. In: Sinatra RS, de Leon-Cassasola OA, Viscusi ER, Ginsberg B, editors. Acute Pain Management. 
Cambridge: Cambridge University Press; 2009. p. 416-30.

10. Caljouw M, Van Beuzekom M, and Boer F. Patient's satisfaction with perioperative care: development, validation, and application of a questionnaire. British journal of anaesthesia. 2008;100(5):637-44.

11. Ibrahim $\mathrm{M}$ and El Shamaa H. Efficacy of ultrasound-guided oblique subcostal transversus abdominis plane block after laparoscopic sleeve gastrectomy: A double blind, randomized, placebo controlled study. Egyptian Journal of Anaesthesia. 2014;30(3):285-92.

12. Kim AJ, Yong RJ, and Urman RD. The role of transversus abdominis plane blocks in enhanced recovery after surgery pathways for open and laparoscopic colorectal surgery. Journal of Laparoendoscopic \& Advanced Surgical Techniques. 2017;27(9):909-14.

13. Shin H, Oh A, Baik J, Kim J, Han S, and Hwang J. Ultrasound-guided oblique subcostal transversus abdominis plane block for analgesia after laparoscopic cholecystectomy: a randomized, controlled, observer-blinded study. Minerva Anestesiol. 2014;80(2):185-93.

14. Breazu CM, Ciobanu L, Hadade A, Bartos A, Mitre C, Mircea PA, et al. The efficacy of oblique subcostal transversus abdominis plane block in laparoscopic cholecystectomy-a prospective, placebo controlled study. Romanian journal of anaesthesia and intensive care. 2016;23(1):12.

15. Akerman M, Pejčić N, and Veličković I. A Review of the Quadratus Lumborum Block and ERAS. Frontiers in medicine. 2018;5:44.

16. Baidya DK, Maitra S, Arora MK, and Agarwal A. Quadratus lumborum block: an effective method of perioperative analgesia in children undergoing pyeloplasty. Journal of clinical anesthesia. 2015;27(8):694-6.

17. Blanco R, Ansari T, and Girgis E. Quadratus lumborum block for postoperative pain after caesarean section: a randomised controlled trial. European Journal of Anaesthesiology (EJA). 2015;32(11):812-8.

18. Elsharkawy H, Salmasi V, Soliman L, Esa W, and Blanco R. Anterior Quadratus Lumborum Block Versus Transversus Abdominis Plane Block with Liposomal Bupivacaine: A Case Report. J Anesth Crit Care Open Access. 2016;6(1):00214.

19. Jadon A, Motka M, Pati AK, and Sinha N. Postoperative analgesia by transmuscular quadratus lumborum block catheters. Journal of Anesthesia \& Intensive Care Medicine. 2016;1(3).

20. Öksüz G, Bilal B, Gürkan Y, Urfalioglu A, Arslan M, Gisi G, et al. Quadratus Lumborum Block Versus Transversus Abdominis Plane Block in Children Undergoing Low Abdominal Surgery: A Randomized Controlled Trial. Regional anesthesia and pain medicine. 2017;42(5):674-9.

To Cite This Article: Ashraf AA *, Lobna TE, Dalal ES, Nahla MA. A Comparative Study Between Transmuscular Quadratus Lumborum Block And Oblique Subcostal Transversus Abdominis Plane Block For Analgesia Following Upper Abdominal Surgeries.ZUMJ 2019;25(6);898-908.DOi: 10.21608/zumj.2019.10882.11300. 